\title{
League tables, institutional success and professional ethics
}

\author{
Alan Cribb Centre for Public Policy Research, King's College, London
}

\begin{abstract}
League tables are just one example of the growing importance of "institutional success" in the health service. What are the implications of attaching importance to institutional success, and what impact might this have on professional ethics? This paper considers these issues and argues that public policy processes which centre on institutional performance, and which co-opt professional loyalties to this end, shift the balance between person-centred and impersonal standpoints in health care (from the former and towards the latter). There is no attempt to make a global ethical appraisal of this putative shift but rather to raise a matter of concern for those committed to a person-centred conception of professional ethics.
\end{abstract}

(Fournal of Medical Ethics 1999;25:413-417)

Keywords: Professional ethics; person-centredness; institutional success

In a recent article in this journal Tom Sorell ${ }^{1}$ elucidated some concerns about the effects of UK policy-making on the provision of health care. $\mathrm{He}$ identified two recent policy goals: (1) "the containment of public expenditure" and (2) "the promotion of personal responsibility, private ownership and entrepreneurship" ${ }^{2}$ and he divided his account of concerns into two corresponding sections - a short section which identifies some of the moral problems of using accounting and audit mechanisms to contain National Health Service (NHS) expenditure, and a longer argument which challenges the basis, and consequences, of transforming patients into consumers. I am happy to accept both Sorell's general framework and his conclusions but I would like to add some further considerations. I want to highlight some of the effects of promoting an audit and performance culture on the providers of health care, and in particular their ramifications for professional ethics.

In this paper I argue that: (a) a key instrument and effect of the current policy climate is an increased emphasis on "institutional success" ie favourable comparative evaluations of the "per- formance" of the institutions (practices, trusts, units, divisions etc) within which health professionals work; (b) institutional success - along with other factors - constructs and constrains health care professionals' choices in a variety of ways; and (c) one of these ways is to play up the "impersonal" rather than the "person-centred" dimension of professional ethics. In the latter part of the paper I consider the significance of these points - assuming that they are sound - and consider what is involved in ethically appraising this putative shift of emphasis in professional ethics.

\section{League tables, public policy and institutional norms}

Probably the most conspicuous and controversial example of the use of institutional success in public sector policy is the use of league tables. Indeed the controversies about league tables do signal many of the issues I have in mind, and they are a particularly striking and stark manifestation of the growing importance of institutional success, and of the reductionism entailed by using simple measures or rankings to capture relative success or failure. But I am anxious to situate this discussion against a larger backcloth and to use a broader conception of institutional success.

Studies of public sector policy, in the UK and elsewhere, ${ }^{3}$ have identified international trends which I can only summarise here. The two goals that Sorell cites of cost-containment and "responsibilisation" 4 have been held together and pursued through linked processes of institutional and cultural engineering. Devolved management and performance review are the means whereby public policy goals are mediated through institutions and to public sector professionals. The rise of performance review and the audit culture over the past 15 to 20 years has been well documented; it was furthered by the previous UK government's NHS internal market reforms but it is intrinsic to recent models of public management. ${ }^{5}$ Thus the particular form of performance review is not the central issue - they create different patterns of constraint and opportunity but they are all designed to harness the institutional loyalty of 
staff to meet institutional and (hence indirectly) public policy goals. Central to the effectiveness of these mechanisms is the increased co-option of professional consciousness to the ends of institutional success. Sometimes the institutional incorporation of public sector reforms has been accompanied by programmes of staff development designed to disseminate a managerial discourse of performance and budget consciousness. But whether or not this dissemination is pursued deliberately or vigorously some such process is guaranteed by changes in cultures and priorities, and by the intimate connections between individual and institutional fortunes and self-identities.

There has of course always been a question as to how professionals can and should accommodate both the claims of their clients and those of their colleagues and institutional settings (amongst others). What is at stake is perhaps merely an intensification of this issue, but I want to suggest that certain aspects of the new culture of institutional performance can both create deeper dilemmas of professional loyalty and also serve to obscure these dilemmas.

\section{Performance indicators}

Of course the idea of an institution (or virtually anything else) being "successful" is highly ambiguous and contestable. The rows about league tables and "failing" schools and hospitals is enough to illustrate that. But on the other hand the very fact that it is possible to operate with these labels shows that it is in some sense possible (even if not wise) to make global evaluations of institutions and "how they are doing". Clearly such evaluations will be more valid if they consist of a broad profile of considerations, and they should certainly be interpreted and used with great caution but they cannot, strictly speaking, be said to be meaningless. I should also emphasise that I am not relying upon the absurd idea that performance indicators are inherently wrong. $\mathrm{My}$ discussion relates to some potential consequences of certain uses of performance indicators - and to a compound of policy and institutional climates which make performance indicators central to conceptions of professional success. Performance indicators are not inherently wrong but they are inherently reductionist. This is what makes them valuable tools; and it is this which makes it necessary for us to be cautious about their use.

Performance indicators, public image and self image can thus become bound up together. This is obvious, for example, when someone works in what is judged to be a failing hospital, but it applies across the board when funding (through the government or from outside budget-holders) an hence the scope for action is linked to these indica tors and images of institutional performance.

In this context it is reasonable for managers an health professionals to establish (and to attacs weight to) a whole range of results-orientest institutional norms which take into account bow the substantive ends of the institution and also the ways in which these ends are mediated through the various forms of performance review and funding in place. These institutional norms may therefore emphasise the indicators used in the prevailin system of performance review but they will also include other forms of audit and control aimes generally at cost-effectiveness and "quality assugp ance" such as targets, guidelines and formularie

Value conflicts and institutional success I will, somewhat artificially, divide the value cor flicts generated by the increasing salience of inst? tutional success and institutional norms into two sets. The first set - which I am not very interested in here - are those which arise from the potentif distractions from, or clear cut distortions of, the goals of health care. These I will briefly mention but only because they are an important piece of the background to the second set of conflicts. The second set relate to the ways in which a concer for institutional success carries with it a particular orientation to meeting the goals of health carê, which I summarise as a shift towards an "impersonal" standpoint.

The first set of conflicts are roughly speaking the ones which have received publicity as healt care provision has been restructured. They are the dangers of an "enterprise culture" for example, institutional rivalry rather than collaboratioe impression management and public relation rather than democratic accountability, and of the distorted and perverse incentives which car sometimes be created by performance indicator All of these pressures can get in the way of a cons cern for providing health care and can potentialiy lead to clear conflicts between what professionas consider to be good practice and what they acknowledge to be successful.

Institutional success should be a means to a end but it can easily slide into becoming an end i itself. This is not simply because of the instrumenital consideration that institutional success means more scope for doing good. It is because in poliag terms institutional success is meant to be the same thing as delivering good health care - the first set of conflicts points to the possibility of exceptionts rather than to the rule. The challenge, it could be argued, is to try to create a health care system in which these distractions and distortions are mins 
mised or eliminated, in which institutional success and "health care success" are the same thing. But this takes me on to the second set of value conflicts. What if there are values inherent in a concern for institutional success which do serve the goals of health care but which create ethical difficulties for health professionals? The rest of the paper considers this possibility and its implications.

\section{Resource allocation decisions}

The argument is simple, and as will become clear, echoes familiar discussions in ethics more generally. It seems to me that a concern for "successled" institutional norms will inevitably tend towards a more general, statistical, resultsoriented and thereby more impersonal conception of the good that health care serves. It is not that institutional success cannot embrace less impersonal and more finely grained considerations; it is simply that it will tend not to emphasise these things precisely because it is an over-arching value which abstracts from, or aggregates, more particular judgments. The reductionism inherent in being results-oriented, which is built into institutional norms, risks making health professionals less responsive to particular individuals and circumstances.

The most obvious problems which arise concern resource allocation decisions where obligations to specific patients have to be weighed against the claims of a broader population and the cost-effective use of budgets. But analogous tensions arise wherever institutional norms relate to abstract people rather than individual persons, for example when treatment guidelines are delimited by overall or mean benefit or some other statistical or broad brush conception of "health care good". It is possible to construe all of these too as examples in "resource allocation ethics" but as I hope to show in what follows there is a danger that this characterisation - if made too quickly obscures the ethical issues at stake.

The central issue is a familiar one in both personal and professional contexts. How far should we morally differentiate between those close by, those with whom we have self-conscious relationships, and all of the other people who - let us assume - we regard as of equal intrinsic value but to whom we have no particular connection? This issue is most often discussed in relation to personal morality but it crops up in medical ethics when, for example, doctors are asked to reflect on how they should divide their time between patients on their waiting list and other work (research, political lobbying etc) which might benefit people more generally. One way of summarising the question is to ask how far health professionals should divide their time and their attention between "personal" health care and public health or population-centred care. And to express it in these terms illuminates the rather different ethical associations of these two roles; the former emphasising obligations to individuals and the latter a more consequentialist, and in practice utilitarian, orientation. ${ }^{7}$ (This form of expression also makes it clear that any balance will depend upon the specific occupational role.)

I am suggesting that the increasing importance of institutional success shifts the balance towards the population-centred approach to health care; and that it has this effect not simply because of global restructuring, or macro-allocations, but through "restructuring" the subjectivities and identities of health professionals. To the extent that health professionals are more or less selfconsciously co-opted into norms aimed at institutional success their role is re-shaped as a more population-centred and impersonal one. This is not necessarily (or only) because they may be more mindful of a broader population but because their work with individuals is increasingly defined in statistical terms, and in terms of its institutional "added value". This shift towards more population-centred health care is not a mysterious side effect of public policy, rather it seems to be in large measure a deliberate and desired effect of many public management reforms. I would, however, claim that it is a shift that has received insufficient attention in proportion to its importance. Assuming that this shift is taking place how should we appraise its importance for person-centred professional ethics?

\section{Changing the balance of professional ethics?}

To begin to answer this question it is necessary to say more about so-called person-centred health care. Certainly this could itself be subject to extended analysis but I will confine myself to distinguishing three possible components: (a) person-centredness as a recognition of individuality or specificity; (b) person-centredness as a recognition of holism, ie of the range of considerations and contexts which are constitutive of persons; and (c) person-centredness as a recognition of autonomy, ie a concern to respect people as to some degree self-defining and self-creating and to work with them and not just on them. It would be surprising if anyone declared him or herself opposed to person-centredness, given these different possible components and the range of combinations and interpretations available for each of them. But we can imagine a rough line from the 
most minimal (and barely person-centred) point of paying regard to the specific biomedical condition of each individual to increasingly radical interpretations which play up various dimensions of, and responses to, the second and third components. I want to reserve the label "person-centred" for those approaches to health care which are some way down this line and according to which health professionals at least take into account and seek to respond to patients' particular personal and social circumstances and considered preferences. At what point does person-centredness move from being a necessary feature of tailoring effective care to becoming an illegitimate indulgence of some patients at the expense of others?

It depends entirely how one sees the fundamental basis of public sector health care professional ethics. Most people, in practice, expect "lay people" going about their ordinary lives to be partial to those to whom they are connected. By contrast most people hope and expect that certain public sector workers (for example, civil servants) will exercise their official roles impartially. (There are important philosophical debates about if, or why, these expectations are appropriate and warranted but I will not discuss them here.) What is a reasonable assumption to make about practitioners working in the NHS or any other publicly funded health system?

\section{Personal bonds}

Although the literature about partiality is typically linked to discussions of personal bonds and emotional attachments ${ }^{8}$ which do not apply in quite the same way to individuals in occupational roles it is not irrelevant to think of some professionalpatient relationships in analogous terms. For example, longstanding "family doctors" or nurses working with chronic or terminal illness in the community may form understandable, and sometimes reciprocal, attachments. But even leaving this aside it is common for philosophers to argue that the doctor-patient relationship, as a professional-client relationship, is intrinsically partial because the doctor is in many respects the representative of the patient or even, in some respects, an extension" of the patient. For example Sokolowski writes:

“... I submit my own prudence to that of the professional. In a limited way, I hand over the steering of my life to this person.

"The professional's mind in this respect becomes like an expansion of the client's own.... The client has come to the professional, has initiated and established the relationship, and keeps it in being". 9
Similarly Koehn ${ }^{10}$ discusses the relationship trust between professional and client based on the professional's declared commitment to serve the client's good in some specific respect. Are although she argues against "exclusive and zealous professional loyalty" to individual clien $\overline{\overline{\mathrm{g}}}$, and addresses the need for professionals balance their loyalty to clients against the public good, she nevertheless stresses the need for particular loyalties as part of the role-specific obligations of professionals.

\section{Different considerations}

The various ideas of serving the patient's good or being the patient's representative, along with related notions such as being an advocate for the patient, no doubt tell rather different stories about the professional-patient relationship, b $\overrightarrow{y t}$ they all entail that health professionals practise person-centred care in the sense of being responsive to both (a) the range of considerations and circumstances relevant to the patient and (b) the patient's preferences about the direction of care. Very often this will oblige them to explore, and imaginatively enter, the lives and "life-worlds" \&f individuals.

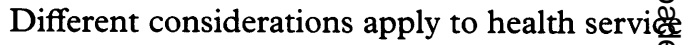
managers or public health doctors (or to other health professionals acting in these, or equivalent, policy-related roles). They do not, and ought not to, represent any particular patients but rather th relevant population of patients. Although they clearly ought to be aware of the variety of conditions and circumstance which need addres 8 ing, and be sensitive to public opinion, they cannot be expected to enter the "life-worlds" of individual patients.

The argument of this paper is that the distinction between the professional-client ro and the policy-related role is being strategicale fudged. What might formerly have been a conflift between two different agents, is increasingR becoming a tension intrinsic to all profession practice because institutional norms construêt and constrain the possibilities of responsivenes Results-oriented institutional norms construct choices in the sense that they provide a language and a set of expectations which favour a "thin" rather than a "thick" conception of the goals of care and which reinforce impersonal rather that person-centred perspectives. They act as a frame which can limit the field of vision necessary for more responsive person-centred care; but eve where professionals see beyond the frame they a as a set of pressures, or constraints, on decisio making. 
For individual practitioners the question is how far, and under what circumstances, should I ignore, "stretch" or challenge results-oriented institutional norms - even where I judge that they are necessary and appropriate overall - in order to advance the cause of a particular patient to whom I have a particular commitment. If, for example, institutional norms have resource allocation objectives built into them are there any circumstances where it might be legitimate for me to "put the blinkers on" or am I always required to think more or less directly about institutional resource allocation?

One way of representing this dilemma is by comparison with the different roles in the legal system. How far should individual professionals act as arbitrators, and how far as advocates? An institutional system can try to achieve impartiality through the impartial judgments of individuals but it can also deploy an adversarial approach in which clients are represented with strong partiality as long as this is within a set of checks and balances. The important thing is that all parties are clear about their role-specific obligations. Within a public health care system a relatively clear division between "arbitration roles" and "advocacy roles" might serve an equally useful function as in the legal system. Certainly there needs to be some shared understanding of what the balance of responsibilities is for different professional roles.

As I have said this is in many respects merely an example of a general problem in ethics. We constantly have to combine and balance attention to our immediate obligations with attention to the broader implications of our actions; and in various ways we attempt to insulate the former from crude forms of outcome-related rationality (and of course one way of doing this is to argue that any defensible consequentialism requires this insulation). Different combinations and balances are called for in different walks of life. For good or ill the new policy context of institutional success destabilises the previously accepted balance. Person-centred professional ethics, and the culture of trust and responsiveness with which it is associated, depend upon fairly routine insulation between particular relationships and the bigger picture; by contrast the performance and audit culture requires that particular relationships are routinely seen through the lens of institutional success.

\section{Conclusion}

In order to evaluate the ethical implications of the increased emphasis on institutional success we need the answer to a number of questions. First there are empirical questions about whether and how the shifts discussed here are reflected on the ground. How are the various tensions in professional ethics experienced in practice, and what are the different responses to them? Second we need to make determinations on general questions about public health policy and health care, including, for example, the kinds and degrees of person-centredness that are desirable. But we also need to resolve some fundamental questions in ethics such as the extent to which forms of partiality are an acceptable or necessary feature of certain social roles.

I would not claim to have answers to any of these questions. All I can do is express a concern about the potentially deleterious effects of policies which not only centre on institutional performance but which also devolve responsibility for institutional success to all health care professionals.

Alan Cribb, PhD, is Deputy Director of the Centre for Public Policy Research, King's College, London.

\section{References}

1 Sorell T. Morality, consumerism and the internal market in health care. Fournal of Medical Ethics 1997;23:71-76.

2 See reference 1: 71 .

3 Van Wart M. Trends in the types of control of public organisations. In: Public integrity annual. Lexington KY: Council of State Governments, 1996.

4 Rose N. Governing the enterprising self. In: Heelas P, Morris P, eds. The values of the enterprise culture. London: Routledge, 1992.

5 Power M. The audit society. Oxford: Clarendon Press, 1997.

6 Heelas P, Morris P, eds. The Values of the Enterprise Culture. London: Routledge, 1992.

7 Karhausen L. From ethics to medical ethics. In: Doxiadis S, ed. Ethics in health education. Chichester: John Wiley and Sons, 1987: 25-35.

8 Kuhse H, Singer P, Rickard M, Cannold L, van Dyk J. Partial and impartial ethical reasoning in health care professionals. Fournal of Medical Ethics 1997;3:226-32.

9 Sokolowski R. The fiduciary relationship and the nature of professions. In: Pellegrino E, Veatch R, Langan J, eds. Ethics, trust and the professions. Washington: Georgetown University Press, 1991: 27, 29.

10 Koehn D. The ground of professional ethics. London: Routledge, 1994. 